\title{
PARACHUTING INJURIES: A STUDY OF 110,000 SPORTS JUMPS
}

\author{
N. ELLITSGAARD, MD \\ Department of Orthopaedic Surgery, Bispebjerg University Hospital, Copenhagen, Denmark
}

\section{ABSTRACT}

A study was undertaken to examine the type, location, incidence and mechanism of injury sustained by amateur parachutists in Denmark during a five-year-period. A total of 110,000 parachute jumps resulted in six $(0.005 \%)$ fatalities and $155(0.14 \%)$ cases, requiring medical treatment. The latter group sustained 176 injuries of which $36.9 \%$ were significant soft tissue lesions and $63.1 \%$ fractures. Landing is the most dangerous part of the parachuting procedure, causing $83.8 \%$ of the accidents, while $9.3 \%$ were caused by faults during opening of the parachute. Based on the injury pattern, some modifications to the procedures and equipment are mentioned. A simplification of the parachute landing fall and the development of safer parachutes may reduce the incidence of casualties. An enforcement of the present regulations is necessary as many injuries are the result of noncompliance with regulations due to ignorance, inexperience or carelessness.

Key words: Parachuting, Aviation, Gravitation, Sports injury epidemiology.

\section{INTRODUCTION}

Sport parachuting has become increasingly popular during recent years. In 1983 approximately 28,000 sport parachute jumps were made in Denmark. This study was undertaken to examine the type, location, incidence and mechanism of injury sustained by amateur parachutists in Denmark during a five-year-period. The demonstration of certain causal relationships might be useful in the prevention of similar injuries in the future. Few studies have been published which illustrate the hazards of parachuting. The populations studied mainly consisted of military parachutists whose way of jumping and the circumstances under which it takes place are different from sport parachuting.

\section{MATERIALS AND METHODS}

From 1979 to 1983110,000 parachute jumps were made by members of the 27 sport parachuting centres which form the Danish Parachute Jumpers Association (DFU). On the basis of reports to DFU on all injured jumpers, the fatalities and the members who had received medical treatment were registered. Jumpers who experience the slightest irregularity during a parachute jump are supposed to notify DFU. Everyone who reported to have suffered injury, completed a questionnaire as a supplement to their initial report.

One hundred and fifty-five jumpers of different experience were registered under this criterion. Two of these did not want to participate and ten jumpers did not need medical treatment. The remaining 143 jumpers had suffered injury on 161 occasions. Their case records were requisitioned from medical centres and the accident reports dealing with the fatalities were provided by DFU. Injuries which did not need medical treatment in other studies are described as "light injury" (Hallel et al, 1975; Pirson et al, 1985). Such injuries are not included in the present study. Prior to their first jump all parachutists had, as members of DFU, passed through a training programme of ten to twenty hours including theory, physical exercises and training of the parachute landing fall.

\section{Technical considerations}

In sport parachuting there are two basic objectives. The first is to use a certain period of time while falling free in the air

Address for correspondence:

Niels Ellitsgaard

Kastelsvej 16 st. th

DK-2100 Copenhagen

Denmark to execute manoeuvres with the body, the so-called "relative work" (RW), before the parachute is deployed. The second is to land as close as possible to the centre of the target on the ground, the so-called "dead centre". In competition, points are awarded for style and for accuracy. The competitors are classified according to their experience. The present study consists of patients who suffered injuries during competitions as well as during training.

\section{Equipment}

The parachutists included in the study wore two parachutes; a main chute on the back and a reserve chute on the chest or on the back. The equipment also comprised helmet, goggles, overalls and boots. Parachutes for sport jumping may be divided in two main groups; automatically and manually deployed chutes. An automatically deployed parachute opens without influence by the jumper. A static line fastened to the floor of the aircraft pulls the canopy out of its sack just after exit. A manually deployed parachute is opened by the jumper, when he wants to terminate his free fall, by pulling a ripcord handle.

During the period in question novice parachutists jumped static-line in a round, slow, non-steerable canopy with slow forward speed. More experienced parachutists jumped free fall in a round or rectangular, faster and steerable canopy with fast forward speed. To use the steerable round PC-chute, 50 manual jumps were demanded, while jumpers started to fly the rectangular chutes after 150 jumps. The rectangular parachute has the aerodynamic characteristics of an aeroplane wing. It is extremely manoeuvrable and may be fully braked in the air. To fly a rectangular chute thus demands a certain experience and a familiarity with the chute to avoid exceeding its capacity.

\section{Nature of jumping}

A knowledge of the phases of the parachute jump and of the technique used in the parachute landing is essential to understand the mechanisms leading to injury. The parachute jump may be divided into the following phases:

1. The exit.

2. The free fall.

3. The opening of the parachute.

4. The canopy descent.

5. The landing.

This study includes injuries related to every single phase.

During landing assuming of the correct "prepare to land 
attitude" and the execution of a good parachute landing fall (PLF) is of great importance. The PLF distributes the landing impact throughout the entire body, in order to reduce the chances of injury to the lower extremities. Depending on body weight, type of parachute, the humidity of the air and other factors, the average speed of descent with a parachute is 6 metres per second, assuming absence of surface wind. In the "prepare to land attitude" the parachutist keeps feet and legs together with hips and knees flexed to $45^{\circ}$. The feet are held at an angle of about $30^{\circ}$ to the ground and the muscles of the lower extremity are slightly tensed to avoid collapse at the moment of impact. The eyes are fixed on the horizon and the arms held straight up with the hands on the risers or grasping the brakes. As the parachutist, facing downwind, makes contact with the ground, he makes no attempt to remain standing, but twists to one side making a PLF with his body following the line of drift, hereby rolling onto the muscular areas of the calf, thigh, buttocks and back. Quick recovery from the PLF is essential to collapse the 'chute fully and thus avoid being dragged by wind gust.

\section{RESULTS}

A total of 110,000 parachute jumps made during a five-year period resulted in six $(0.005 \%)$ fatalities and $155(0.14 \%)$ cases, requiring medical treatment. The latter sustained 176 injuries of which $36.9 \%$ were significant soft tissue lesions and $63.1 \%$ fractures. The types and anatomical distribution of injuries appear in Table I. For patients with multiple lesions, each lesion was considered individually. One hundred and five $(59.7 \%)$ of the 176 injuries involved the lower extremities; of these 44 were ankle fractures. $10.2 \%$ of the injuries involved the spine. The upper extremities were affected in $17 \%$ of the cases; of these $9.1 \%$ were fractures of the wrist.

The causes of injury related to the experience of the jumpers appear in Table II. The landing is the most dangerous part of the jump, causing $83.8 \%$ of the accidents, while $9.3 \%$ were caused by faults during opening of the parachute. Table III shows the distribution of 182 injuries (fatalities included) related to the causes of injury in 161 jumps. Concerning the causes of injury during landing, the analysis is based on the jumper's own assessment of the situation. Often, landing injuries are caused by more than one factor. Male to female ratio of jumpers with injuries was $3.74: 1$. The mean age was 29.3 years, range $16-62$ years.

\section{DISCUSSION}

Earlier studies illustrating the hazards of parachuting consisted mainly of military parachutists (Ciccone et al, 1948; Davis, 1964; Hallel et al, 1975; Neel, 1951; Petras et al, 1983; Pirson et al, 1985). Certain factors, however, distinguish military parachutists from sport parachutists. The former jump from lower altitudes, in larger groups and from faster moving aircrafts than do sport jumpers. The military jumpers also carry more equipment and generally jump static line rather than free-fall. They jump in all kinds of weather over unfamiliar dropzones. In both populations the majority of the injuries takes place during landing.

During exit and free-fall the sport parachutist is not exposed to as many hazards caused by his surroundings as is the military paratrooper, a difference which is demonstrated by the present study. Only five jumpers were injured during free-fall. The "relative-work" in itself did not cause injuries, whereas four of the jumpers were killed in solo accidents. The fatalities were caused by failure to activate the parachute, apparently in spite of sufficient time to do so. On one occasion neither of the two parachutes were activated after RW. This might have been caused by a loss of altitude awareness, as the jumper did not use a visual altimeter (DFU accident report). The three other jumpers had malfunction of the parachute and failed to complete the emergency procedure, as they did not activate their reserve parachute after break-away. Wearing awkward gloves or large goggles, the jumpers might have had difficulties in finding the ripcord handle (DFU accident reports).

During canopy opening fifteen jumpers were injured. Two fatalities happened due to violation of the existing procedures. One jumper who had a partial malfunction of

TABLE I

Anatomical distribution of 176 injuries due to parachute jumping.

Contusions Sprains Ligament Dislocations Wounds Fractures Others $\quad \begin{gathered}\text { tear } \\ \text { L }\end{gathered}$

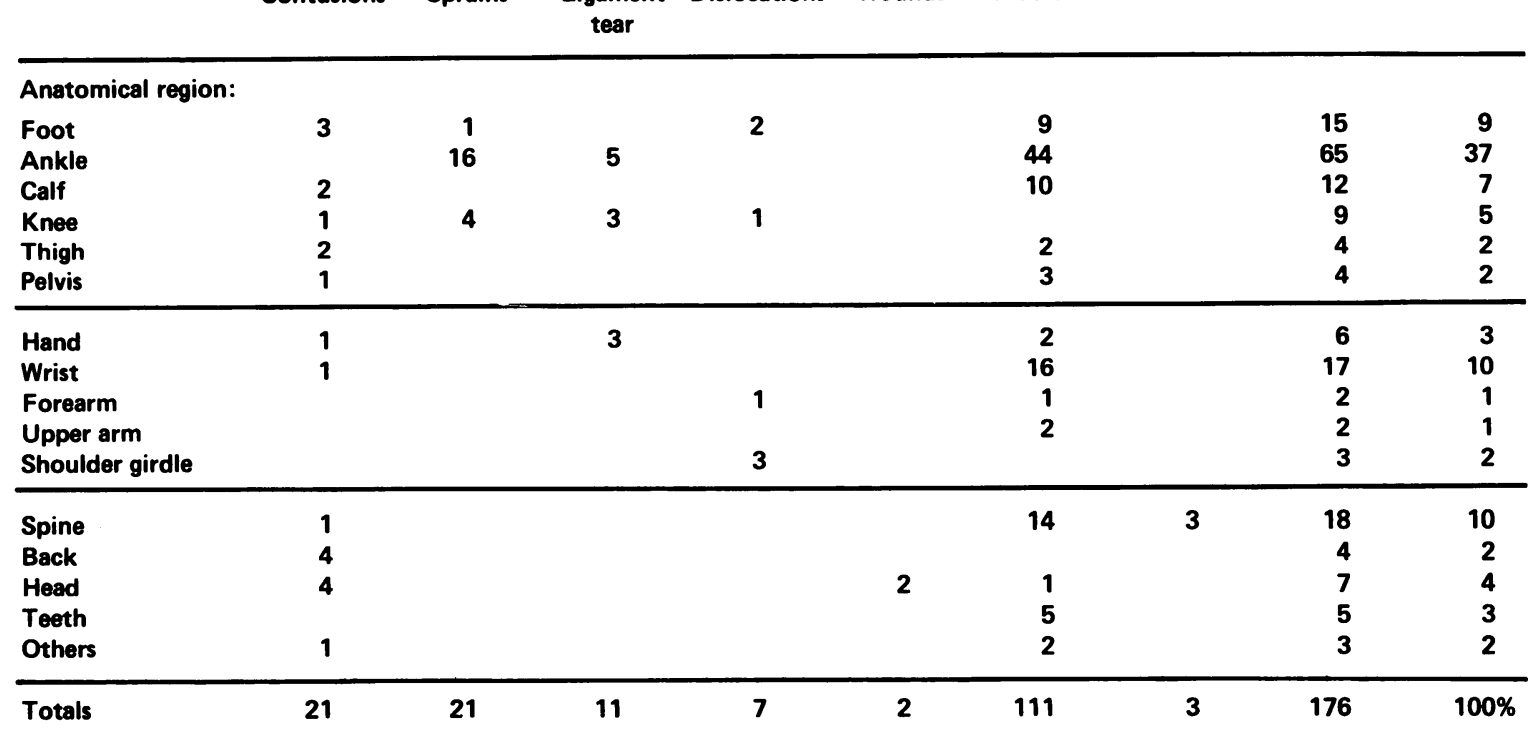


TABLE II

The cause of injury or fatality related to the experience of the parachuters (number of jumps performed earlier). $\mathbf{N}=161$.

Experience:

$\begin{array}{lllllllll}1.5 & 6.50 & 51 \cdot 100 & 101 \cdot 200 & 201.500 & 501 \cdot 1000 & >1000 & \text { Total } & \%\end{array}$

Causes related to:

\begin{tabular}{|c|c|c|c|c|c|c|c|c|c|c|}
\hline 1. & The exit & & 1 & & & & & & 1 & 0.6 \\
\hline 2. & The free fall & & & 1 & 1 & & 1 & 2 & 5 & 3.1 \\
\hline 3. & The opening of the canopy: & & & & & & & & & \\
\hline & Malfunction & 1 & & & & & 1 & & 2 & 1.2 \\
\hline & Opening shock & & 3 & 2 & & 1 & & 1 & 7 & 4.4 \\
\hline & Poor body position & & 3 & & & 2 & & 1 & 6 & 3.7 \\
\hline 4. & The canopy descent & & & & 1 & 1 & & & 2 & 1.2 \\
\hline 5. & The landing: & & & & & & & & & \\
\hline & Increased vertical velocity & & & 2 & 4 & 4 & & 1 & 11 & 6.8 \\
\hline & Disregerd of proper procedure & 1 & 4 & 5 & 13 & 1 & & & 24 & 14.9 \\
\hline & Increesed surface wind velocity & 2 & 2 & 1 & & 2 & 1 & & 8 & 5.0 \\
\hline & Oscillation & & 7 & 1 & 3 & & & & 11 & 6.8 \\
\hline & Improper body position & 20 & 7 & 4 & 4 & 1 & 1 & & 37 & 23.0 \\
\hline & Improper PLF & 3 & 4 & 3 & 2 & 2 & 1 & & 15 & 9.3 \\
\hline & Major obstacles & 1 & 4 & 1 & 3 & & & & 9 & 5.6 \\
\hline & Minor obstacles & 3 & 9 & 2 & 4 & 2 & & & 20 & 12.4 \\
\hline 6. & Others & 1 & 1 & & & & 1 & & 3 & 1.9 \\
\hline
\end{tabular}

TABLE III

Anatomical distribution of 182 injuries related to the causes of injury in 161 parachute jumps (fatalities included). $N=182$.

Foot Ankle Calf Knee Thigh Pelvis Wrist Hand/ Back/ Head Teeth Others Deaths Total

Causes related to:

1. The exit

1

2. The free fall

Arm Spine

3. The opening of the canopy:

Malfunction

Opening shock

Poor body position

2

2

4. The canopy descent

1

1

2

5. The landing:

Increased vertical velocity

Disregard of proper procedure

Increased surface wind velocity

Oscillation

Improper body position

Improper PLF

Major obstacles

Minor obstacles

$\begin{array}{rr}3 & 2 \\ 5 & 9 \\ & 5 \\ 2 & 3 \\ 1 & 24 \\ 1 & 6 \\ & 3 \\ 3 & 12\end{array}$

$\begin{array}{ll}1 & \\ 1 & \\ 1 & 1 \\ 2 & \\ 2 & 2 \\ 1 & 1 \\ 1 & \\ 2 & 3\end{array}$

6. Others

(20)

1

his main parachute failed to throw it off prior to the release of his reserve parachute, resulting in entanglement of the suspension lines. On another occasion a novice jumper had a malfunction of the static line. She did not attempt to release the reserve as expected and her main parachute did not open in time to save her life. On three occasions parachutists had an extremity entangled in the suspension lines as the result of a poor body position as the parachute was torn out of its pack. Before they were able to extricate themselves, the slack lines were pulled taut, resulting in violent torsion traumas of the extremities. Three others were hit in the face and neck by the lines or the harness leading to fractures of the teeth or friction burns. Also minor injuries may take place during canopy opening. Four 
jumpers fractured their incisors on the altimeter placed on a high chest reserve as the main canopy opened violently. (Jumpers using rectangular chutes wear both parachutes on the back, thus avoiding this problem.) One jumper suffered rib fractures by a violent chest reserve opening, while two others were hyperextending the spine during opening of a low placed chest reserve resulting in constant back pain without radicular symptoms. The conditions were regarded as facet syndromes and both were treated satisfactorily with manipulation (Table I, other spine injury). During canopy descent only two jumpers were injured as a result of the "stolen air" phenomenon (Davis, 1964).

It is upon striking the ground that most injuries occur. As in other studies (Neel, 1951; Ryan et al, 1965) increased surface wind velocity and oscillation caused trouble to the jumpers. On eleven occasions jumpers were injured secondary to further vertical acceleration. Several of these jumpers could have been saved from injury if they had assumed the proper landing attitude as taught (Table II). The most favourable drop zone has a surface of soft earth or sandy soil. A rough and stony terrain or slippery oblique surfaces are bad drop zones, which in spite of the use of a correct landing technique, caused many injuries to the lower extremities (Minor obstacles, Table III). The presence of major obstacles on the ground, such as buildings, trees, cows and electric wires further endangered the jumpers during landing (Table III). Major obstacles must be avoided by proper slipping on the part of the jumper. During competitions the jumper may be tempted to violate the normal landing procedure in his aim to hit the dead centre. Several jumpers tried to land in the direction of wind or hesitated to turn the parachute against the wind, the latter resulting in an oscillation during landing. Other jumpers using steerable rectangular parachutes braked their chute too violently over the dead centre. This deprives the chute of its lift and they experienced a partial free-fall, often from 8-10 metre's altitude. These typically were experienced jumpers with up to $\mathbf{2 0 0}$ jumps prior to the accident who had recently changed to this new type of parachute (Table II).

The majority of jumpers who were injured failed to assume a good body position for the landing or to make the PLF. Beside the correct body position, typically four others were assumed, namely: A too loose or a too stiff position, landing with legs apart or on one leg, "reaching for the ground". Jumpers who were violently activating their brakes landed in the loose attitude with their hands downwards below the level of the buttocks, so fracturing the wrists (Table III). Too straight or too rigid body positions were most frequently found among beginners. Scared by seeing the ground rapidly approaching, the jumper stiffened up. Landing with the legs apart was a frequent landing position. This will by the least oscillation cause one leg to strike the ground first. The downward force is then transmitted somewhere between the ankle and knee, depending upon the angle of fall, resulting in a fracture. The fact that ankle fractures were the dominating fracture (Table 1) might have protected the jumpers from damage to more proximal parts of the lower limb. Harmful forces were dissipated as the ankle fractured. In fact this study had only two fractures of the femur which contradicts the allegation that fractures of the femur are a typical parachute landing injury (Salai et al, 1983).

Eighty-four per cent of the injuries in the present study were caused by factors related to the landing. As in other studies (Hallel et al, 1975; Straiton et al, 1986) it seems obvious that a great percentage of the injuries described above happened due to failure to follow recommended procedures or to a lack of proper instruction and training. The problem then in the case of many landing errors was one of non-compliance with regulations due to ignorance, inexperience or carelessness. As a consequence the DFU is now revising existing regulations and the education of new instructors. The training course will be modified to standardise the education of student jumpers all over the country and to ensure a continuity between theory and practise.

In order to avoid confusion and inexpedient, instinctive reactions during landing, the beginner is now taught a simplified landing attitude. Shortly before contact with the ground the jumper modifies his "prepare to land attitude" to the so-called "banana attitude", swaying his body in the line of drift, still keeping his legs and feet together with a slight flexion in hips and knees (Fig. 1). Striking the ground in this position, the jumper has already initiated the PLF (Fig. 2) and left out hazardous alternatives to a safe landing.

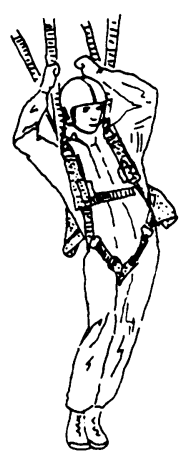

Fig. 1: Prepare to land attitude.
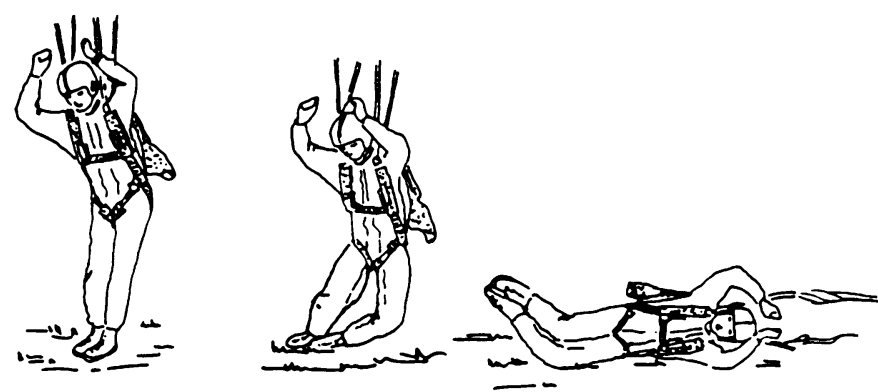

Fig. 2: The parachute landing fall.

In recent years the steerable rectangular parachute has been developed further and an altered model may now be used by novice jumpers. It still has the well-known qualities of an aeroplane wing, giving a safe landing as the jumper is always facing the wind. The alteration on this model implies that it cannot be braked fully. The chute will always be ensured sufficient lift to avoid stalling. The use of radio guidance has proved promising. Offering all student jumpers this kind of supervision might spare them many injuries as an instructor present on the landing field in this way may comment simultaneously on the jump and advise his apprentice when necessary.

A final comment should be made on the fractures of the ankle mortice and the tibia. Attention should be paid to the prevention of these fractures in view of their relative frequency and the protracted treatment they require, being 
weight-bearing structures. DFU recommends the use of solid boots which protect and support the ankle during landing. The bootleg must reach at least five centimetres proximal to the ankle mortice. The actual choice of boots seems however to be rather arbitrary. A classification of the ankle fractures in this study on the basis of roentgenographic findings might further elucidate the mechanisms of injury and lead to some useful recommendations based on facts.

\section{References}

Ciccone, R. and Richman, R. M., 1948 "The mechanism of injury and the distribution of three thousand fractures and dislocations caused by parachute jumping". J.Bone Jt.Surg. 30A: 77-97.

Davis, W. R., 1964 "Parachuting injuries: Their prevention". Milit.Med. 129: 1071-1076.
Deitrick, R. W., Holmes, D. L. and Murphy, M., 1985 "Physiological characteristics of elite sport parachutists". Aviat.Space Environ.Med. 56: 351-357.

Dekleva, N., Grijic, M. and Wilhelm, B., 1965 "Foot stress in parachuting". Med.Tribune: February 24, p. 10.

Hallel, T. and Naggan, L., 1975 "Parachuting injuries: A retrospective study of 83,718 jumps". J.Trauma 15: 14-19.

Neel, S. H., 1951 "Medical aspects of military parachuting". Milit.Surg. 108: 91-105.

Petras, A. F. and Hoffman, E. P., 1983 "Roentgenographic skeletal injury patterns in parachute jumping". Am.J.Sports Med. 11: 325-328.

Pirson, J. and Verbiest, E., 1985 "A study of some factors influencing military parachute landing injuries". Aviat.Space Environ.Med. 56: 564-567.

Ryan, A. J. and Thomas, C. L., 1965 "Sport parachuting and skydiving". JAMA 194: 259-263.

Salai, M., Israeli, A., Chechick, A., Horoszowski, H. and Farine, I., 1983 “Lower limb injuries in parachuting". Int.J.Sports Med. 4: 223-225.

Straiton, N. and Sterland, J., 1986 "Sponsored parachute jumps - Can they cause prolonged pain?". Brit.J.Sports Med. 20: 60-61.

\title{
THE SIXTH CONGRESS OF SPORTS MEDICINE OF THE A.Z.SINT-JAN
}

BRUGGE, BELGIUM - October 16th \& 17th, 1987

\section{Friday, 16th}

Sessions 1 \& 2 Mechanical lesions in the foot in sports.

including Mr. B. Helal - "A survey of problems encountered in the sportsman's foot, together with their management"

Dr. P. N. Sperryn - "The sportsman's shoes"

Session 3 Sports and heart

Session 4 Miscellaneous

\section{Saturday, 17th}

Session 5 Soft tissue pathology in the shoulder; problematics and diagnosis

Session 6 Therapy of soft tissue pathology in the shoulder

All lectures will be translated simultaneously (Dutch, French, English). A programme is available for the spouses of delegates on Friday, 16th October and a banquet will be held the same evening. For more information and for the final programme and registration forms please write to:

\author{
SECRETARIAAT SPORTGENEESKUNDIGE DAGEN \\ Revalidatiecentrum \\ A.Z.Sint-Jan \\ Ruddershove 10 \\ B-8000 BRUGGE \\ BELGIUM
}

